\title{
GENERATION OF UNUSUALLY LARGE RUNUP EVENTS
}

Chuan Li, Oregon State University, lic@oregonstate.edu; H. Tuba Özkan-Haller, Oregon State University, tuba.ozkanhaller@oregonstate.edu; Gabriel García-Medina, Oregon State University, ggarcia@coas.oregonstate.edu; Robert A. Holman,

Oregon State University, holman@coas.oregonstate.edu; Peter Ruggiero, Oregon State University,

pruggier@coas.oregonstate.edu; Treena Jensen, National Weather Services, Treena.Jensen@noaa.gov; David Elson, National Weather Services, dave.elson@noaa.gov; William R. Schneider, National Weather Services, bill.schneider@noaa.gov

\section{SUMMARY}

We present an examination of unusually large runup events that were observed on January 16, 2016 on the west coast of the United States. Although these events resemble small tsunamis, no earthquake or significant atmospheric disturbances were observed during this time. Coincidental observations of long and rapidly increasing peak wave periods and moderately large wave heights both on- and off-shelf suggest that long and large swells generated by distant storms were possibly the cause of these events.

\section{BACKGROUND}

The January 16 large runups events were observed at several locations between northern California and Washington. At least two of these events, nearly $450 \mathrm{~km}$ apart, were captured on video camera (one at Charleston and one at Pacific Beach, see Figure 1). Video footage show that these events resemble small tsunamis in the sense that they were single large waves that reach much further (on the order of $100 \mathrm{~m}$ ) inland than normal wave runups (see videos at https://youtu.be/RPypT9dOvSY and https://youtu.be/HSCCe1y6-b8).

\section{ANALYSIS}

We examine water level, wave, and meteorological observations both on and offshore from the two locations of interest. Tsunami-like events can be generated by large atmospheric disturbance traveling at the shallow water wave speed (Monserrat et al. 2006). However, at the time of these events no significant atmospheric pressure and wind anomaly were recorded at nearby stations. In addition, no strong storm fronts on the shelves were observed from Next-Generation Radar reflectivity. Off-shelf bottom pressure sensors indicate that presence of earthquakes was unlikely (Figure 2a). The strongest signatures coincident with the two events turn out to be long and rapidly increasing peak wave period and moderately large wave heights recorded both far $(500 \mathrm{~km})$ offshore (Figure $2 \mathrm{~b}$ ) and near the locations of the events (NDBC stations 46211 and 46015 in Figure 1).

\section{SIGNIFICANCE}

Large and unexpected runup events are the leading cause of death by drowning in the region discussed in this work. Much like with rogue waves in deep water, we currently do not have a sufficient understanding nor the ability to predict these events. Although drowning incidents often occur during even much smaller runup events, the rare events of January 16, 2016 allow us an opportunity to better understand the mechanisms that link distant events to nearshore occurrences of large and unexpected runups. In addition, these events may aid us in developing a predictive capability of future similar events (e.g. by using peak wave period and wave heights from distant stations, or bottom pressure signatures as in Figure 2a).

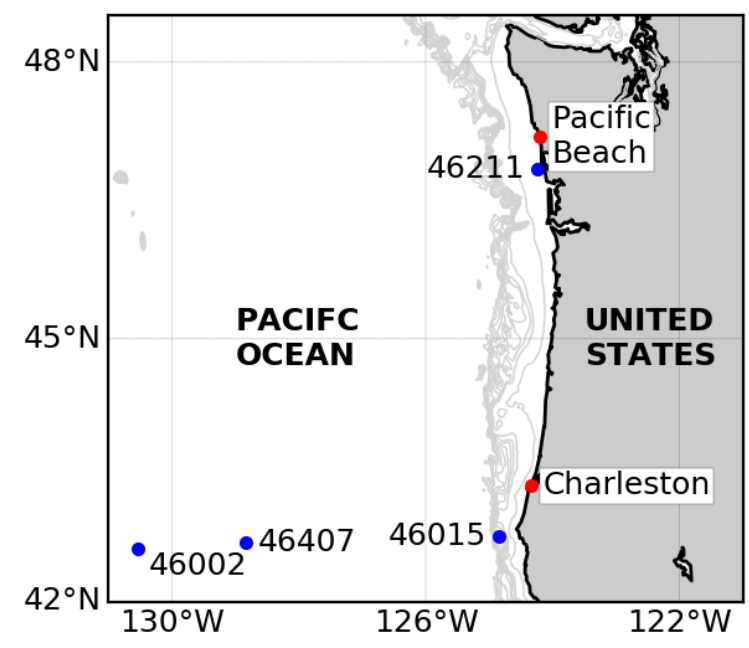

Figure 1 - Locations of events and observation stations

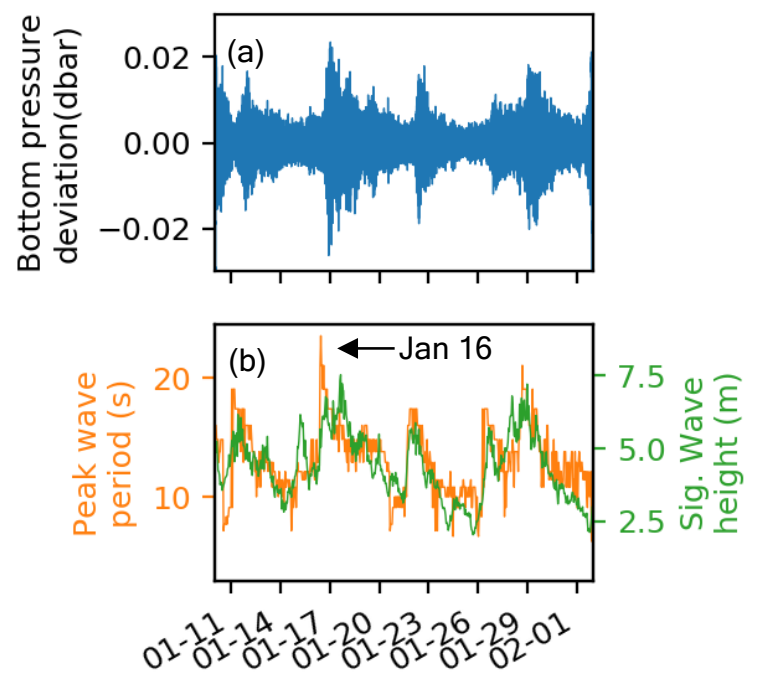

Figure 2 - (a) bottom pressure at station 46407, (b) peak wave period and wave height at station 46002

\section{REFERENCES}

Monserrat S, Vilibić I, Rabinovich AB (2006): Meteotsunamis: atmospherically induced destructive ocean waves in the frequency band. Nat Hazard Earth Syst Sci 6:1035-1051 